\title{
Multifunctional Actions of Approved and Candidate Stroke Drugs
}

\author{
Jens Minnerup and Wolf-Rüdiger Schäbitz \\ Department of Neurology, University of Münster, Albert-Schweitzer-Straße 33, 48149 Münster, Germany
}

\begin{abstract}
Summary: Ischemic stroke causes brain damage by multiple pathways. Previous stroke trials have demonstrated that drugs targeting one or only a few of these pathways fail to improve clinical outcome after stroke. Drugs with multimodal actions have been suggested to overcome this challenge. In this review, we describe the mechanisms of action of agents approved for secondary prevention of ischemic stroke, such as antiplatelet, antihypertensive, and lipid-lowering drugs. These drugs exhibit considerable properties beyond their classical mechanisms, in-
\end{abstract}

cluding neuroprotective and neuroregenerative properties. In addition, candidate stroke drugs currently studied in clinical phase III trials are described. Among these, albumin, hematopoietic growth factors, and citicoline have been identified as promising agents with multiple mechanisms. These drugs offer hope that additional treatment options for the acute phase after a stroke will become available in the near future. Key Words: Stroke, drug therapy, mechanisms, neuroprotection, neuroregeneration.

\section{INTRODUCTION}

Despite the tremendous mortality and morbidity of stroke, treatment options remain limited. Many pathophysiological key mechanisms of cerebral ischemia have been identified in recent years, but drug treatment targeting one or a few of these mechanisms has failed to improve clinical outcome after stroke. The most plausible reason for this failure is the multiplicity of mechanisms involved in causing neuronal damage during ischemia. Drugs targeting a multimodal mode of action could potentially overcome this dilemma, and have recently been shown to provide a remarkable benefit in preclinical studies.

The only drug approved for the acute phase of ischemic stroke is recombinant tissue plasminogen activator (rtPA) - which, however, predominantly acts by targeting a single mechanism, the lysis of the intravascular clot. Antiplatelet, antihypertensive, and lipid-lowering therapies are approved for secondary stroke prevention. In contrast to rtPA, additional effects of these drugs beyond their classical mechanisms are suggested, particularly because prestroke use of drugs for secondary stroke prevention was found to be associated with less

Address correspondence and reprint requests to: Jens Minnerup, University of Münster, Department of Neurology, Albert-Schweitzer-Straße 33, 48149 Münster, Germany. E-mail: minnerup@uni-muenster.de. Or Wolf-Rüdiger Schäbitz; e-mail: schabitz@uni-muenster.de. severe deficits when a stroke occurred. Moreover, animal experimental studies confirmed that antiplatelet, antihypertensive, and lipid-lowering drugs exert multimodal actions including neuroprotective and neuroregenerative properties. We review these approved stroke drugs with a focus on their multimodal modes of action. In addition to drugs for secondary prevention of stroke, further agents were identified that interfere with various pathophysiological mechanisms in cerebral ischemia. Some of these drugs were extensively tested in preclinical stroke studies and showed promising results regarding infarct size reduction and functional recovery enhancement. Those candidate stroke drugs with multiple mechanisms in acute or chronic stroke that were successfully translated into clinical phase III trials are also described in this review.

\section{APPROVED DRUGS FOR SECONDARY STROKE PREVENTION}

\section{Antiplatelet agents}

Platelet aggregation is important in stroke development, both in the pathogenesis of atherosclerosis and in the occurrence of acute cerebral artery occlusions. ${ }^{1}$ The initial step is platelet adhesion to the arterial wall, a result of endothelial damage. ${ }^{2}$ Platelet adhesion is promoted by several factors, including as von Willebrand factor, fibrinogen, and subendothelial collagen. ${ }^{2}$ Afterwards, adhesion platelets are activated mainly by thromboxane 
Table 1. Mechanisms of Action of Approved and Candidate Drugs for Stroke

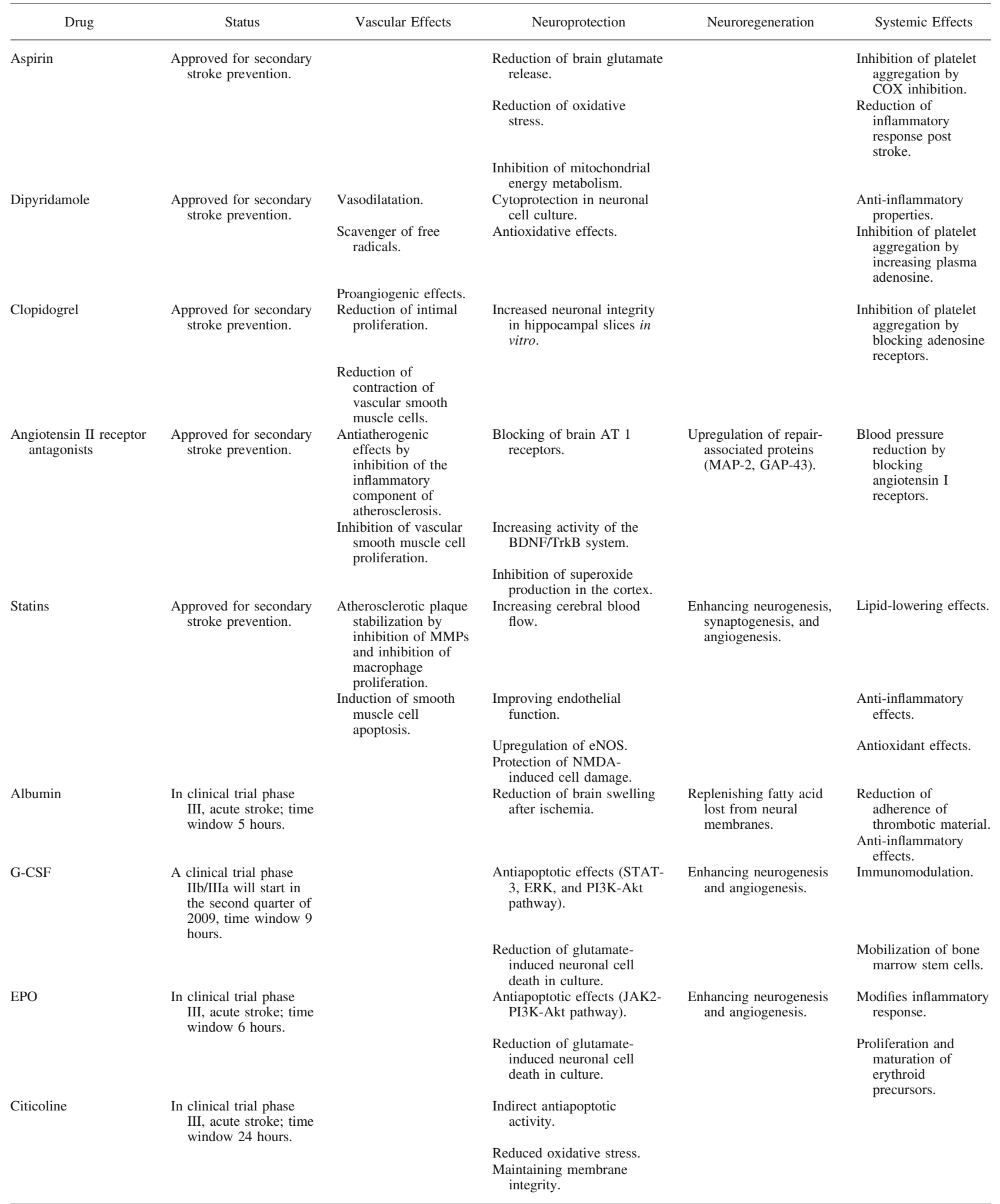

AT $1=$ angiotensin type $1 ; \mathrm{BDNF}=$ brain-derived neurotrophic factor; $\mathrm{COX}=$ cyclooxygenase; eNOS = endothelial nitric oxide synthase; EPO = erythropoietin; $\mathrm{ERK}=$ extracellular signal-regulated kinase; G-CSF = granulocyte colony-stimulating factor; $\mathrm{MMP}=$ matrix metalloproteinase; PI3K = phosphatidylinositol 3-kinase; STAT-3 = transcription factor (signal transducer and activator of transcription type 3); TrkB = tyrosine receptor kinase type B. 
A2, thrombin, and adenosine diphosphate. ${ }^{3}$ This process requires the cyclooxygenase (COX)-mediated metabolism of arachidonic acid to prostaglandin $\mathrm{H} 2$ ( $\mathrm{PGH} 2$ ), which in turn is processed to thromboxane A2. ${ }^{3}$ Platelet activation results in platelet aggregation due to the conversion of the glycoprotein IIb/IIIa receptor to a form that binds fibrinogen and other adhesion molecules. ${ }^{1}$ Based on the relevance of platelet aggregation in stroke pathogenesis, its inhibition became a target for therapeutic intervention. The results of many trials that evaluated antiplatelet agents in stroke led to recommendations that all stroke patients not requiring anticoagulation should receive antiplatelet therapy. ${ }^{4}$ Aspirin, clopidogrel, and the combination of aspirin and extended-release dipyridamole are accepted treatment options. ${ }^{4}$

Aspirin. Aspirin was the first antiplatelet drug used for secondary prevention in ischemic stroke. ${ }^{5}$ Within the last 20 years, the effectiveness of aspirin for recurrent ischemic stroke prevention has been shown in several trials. $^{6,7}$ The best-characterized effects of aspirin in the prevention of cardiovascular diseases are based on its platelet inhibitory functions. ${ }^{8}$ After diffusion through the cell membranes of platelets, aspirin first binds and then acetylates a specific serine residue of COX, thereby preventing the conversion of arachidonic acid to $\mathrm{PGH} 2$ and thus also preventing the formation of thromboxane A2.

Apart from the antiplatelet effects, there is growing evidence for direct neuroprotective properties of aspirin (Table 1). ${ }^{9-14}$ In animal models of focal cerebral ischemia, both pretreatment and administration of aspirin after the onset of ischemia is neuroprotective, as indicated by infarct size reduction for aspirin doses between $15 \mathrm{mg} / \mathrm{kg}$ and $80 \mathrm{mg} / \mathrm{kg}$ body weight. ${ }^{9,13,15}$ Reduction of brain glutamate release after ischemia appears to be an important mechanism by both NF- $\kappa \mathrm{B}$ dependent and independent pathways. ${ }^{9,11,12}$ Glutamate toxicity may additionally be reduced by aspirin-mediated inhibition of prostaglandin (PG) formation. Prostaglandins synthesized by COX enhance the release of glutamate from astrocytes. Its decreased composition may therefore abate glutamatergic neurotoxicity. ${ }^{16}$ In vitro experiments showed that aspirin also prevents neurotoxicity by inhibition of the atypical protein kinase $\mathrm{C} \zeta$, which is a downstream signal in NMDA-induced neuronal cell death. ${ }^{17}$ Moreover, aspirin exerts neuroprotective properties through reduction of oxidative stress and by inhibitory effects on mitochondrial energy metabolism. ${ }^{18,19} \mathrm{Neu}-$ roprotection by aspirin was also suggested by clinical studies showing that prestroke use of aspirin reduced stroke severity. ${ }^{20,21}$ Increasing evidence suggests that inflammation plays a role both in atherosclerosis with subsequent stroke and in poststroke morbidity and mortality. ${ }^{22-24}$ Aspirin was found to be associated with lower values of inflammatory parameters after stroke. ${ }^{25,26}$ To date, however, the relevance of these anti-inflammatory effects for stroke prevention remains unknown.

Dipyridamole. Dipyridamole is available in immediate-release form, usually given in doses between 50 and $100 \mathrm{mg}$ three times per day, or as a fixed combination of $25 \mathrm{mg}$ aspirin and $200 \mathrm{mg}$ extended-release dipyridamole (ER-dipyridamole), given two times per day. In comparison of placebo to three active treatment groups (aspirin alone, ER-dipyridamole alone, and the combination of aspirin and ER-dipyridamole) in secondary prevention of ischemic stroke, the single use of either aspirin or ER-dipyridamole was superior to placebo, and the combination of aspirin and ER-dipyridamole was superior to either drug alone. ${ }^{27} \mathrm{~A}$ meta-analysis of six trials comparing the combination of dipyridamole and aspirin (also including the immediate-release formulation) to aspirin alone confirmed these findings, revealing a significantly lower risk of serious vascular events when aspirin was combined with dipyridamole. ${ }^{28}$

Dipyridamole exerts antiplatelet effects by inhibition of the adenosine uptake in erythrocytes and the attenuation of adenosine catabolism, both of which result in increasing plasma concentrations of adenosine, an inhibitor of platelet aggregation. Dipyridamole is also known to act via adenosine as a potent vasodilator, mainly in coronary arteries. ${ }^{29}$ The effect of dipyridamole on cerebral blood flow is, however, not fully understood. ${ }^{30,31}$ Dipyridamole possesses antithrombotic properties in the vessel wall by enhancing the production of the endogenous platelet inhibitor prostacyclin, thereby preventing platelet adhesion to the endothelium. ${ }^{32,33}$ Damage caused by hydrophilic and hydrophobic radicals can be prevented by the scavenger properties of dipyridamole. ${ }^{34}$ Dipyridamole inhibits oxidation of low density lipoprotein (LDL) and may prevent the development of atherosclerosis. ${ }^{35}$ In various neuronal cell culture models dipyridamole was cytoprotective. ${ }^{36,37}$ Dipyridamole also exerted neuroprotective properties in an embolic stroke model. ${ }^{38}$ The underlying mechanisms of neuroprotection remain unknown. Both adenosine effects and antioxidative effects are assumed to be relevant. ${ }^{36,39}$ Further potential mechanisms of dipyridamole in stroke pathophysiology include anti-inflammatory actions and proangiogenic effects. $^{40,41}$

Clopidogrel. In a large clinical trial, clopidogrel reduced the composite endpoint of stroke, myocardial infarction, or vascular death compared with aspirin in high-risk patients. ${ }^{42}$ In patients with peripheral arterial disease, clopidogrel is superior to aspirin in terms of stroke prevention. ${ }^{42}$ As recently shown, there were no significant differences in secondary stroke prevention when clopidogrel was compared with the combination of aspirin and ER-dipyridamole. ${ }^{43}$

Clopidogrel is a second-generation thienopyridine. 
Clopidogrel irreversibly blocks the P2Y12 receptor, an adenosine receptor located on the surface of platelets, thereby preventing platelet aggregation by inhibition of the glycoprotein IIb/IIIa complex. ${ }^{44}$ Clopidogrel itself has no antiplatelet activity and needs to be oxidated by the hepatic cytochrome P-450 system to an active metabolite. ${ }^{45}$ Beyond the inhibition of thrombus formation, animal experimental studies suggested direct effects of clopidogrel on arterial vessels, such as a reduced intimal proliferation after arterial injury and reduced serotonin and endothelin-1-mediated contraction of vascular smooth muscle cells (Table 1). ${ }^{46-48}$ In vitro studies measuring the population spike amplitude in murine hippocampal slices after a hypoxic episode found that pretreatment with clopidogrel increased neuronal integrity, compared with control treatment, taken as indication of a neuroprotective capacity of clopidogrel. ${ }^{49}$

\section{Antihypertensive drugs}

High blood pressure is well known as an important risk factor for ischemic stroke. Lowering an elevated blood pressure is recommended for primary prevention, as well as for prevention of recurrent stroke. ${ }^{4}$ Several classes of antihypertensive drugs were found to be effective in secondary stroke prevention, and to date there is no recommendation clearly favoring a special antihypertensive drug. ${ }^{4,50}$ Angiotensin II receptor antagonists were, however, found to be superior to a beta-blocker (losartan vs atenolol) in primary prevention and to a calcium channel blocker (eprosartan vs nitrendipine) in secondary prevention of ischemic stroke. ${ }^{51,52}$ Because blood pressure reduction was similar in both comparisons, other mechanisms were assumed. Angiotensin II receptor antagonists reduce blood pressure by inhibition of the renin angiotensin system. Renin catalyzes the cleavage of angiotensinogen to angiotensin I, which in turn is cleaved by the angiotensin converting enzyme to its active form angiotensin II. ${ }^{53,54}$ The appropriate stimulus for renin production by the kidney is glomerular hypoperfusion. ${ }^{53}$ Angiotensin II acts via the specific angiotensin II receptors AT1 and AT2 ${ }^{55}$ The latter is less well characterized, whereas AT1 is well known to mediate vasoconstriction, aldosterone-mediated sodium and water retention, left ventricular hypertrophy, and growth in the arterial wall. ${ }^{56}$ Angiotensin II receptor antagonists counteract these mechanisms by blocking the angiotensin I receptor, which results in a lowered blood pressure. ${ }^{57}$

Beyond lowering blood pressure, other mechanisms of AT1 receptor blockers in stroke pathophysiology have been suggested (Table 1). In various animal experimental studies of focal cerebral ischemia, neuroprotective properties have been demonstrated. ${ }^{58-60}$ Effects of AT1 receptor blockers on brain AT1 receptors were suggested to mediate these neuroprotective characteristics. ${ }^{58,61}$ The ability of different AT1 receptor blockers to cross the blood-brain barrier is controversial, however. ${ }^{62,63}$ Candesartan was shown to enhance the TrkB receptor of brain-derived neurotrophic factor (BDNF), a neurotrophin well known for its neuroprotective effects. ${ }^{64}$ Additionally, candesartan inhibited the increase of superoxide production in the cerebral cortex after cerebral ischemia in mice. ${ }^{65}$ Expression of the proinflammatory cytokine tumor necrosis factor $\alpha(\mathrm{TNF} \alpha)$ and the proinflammatory marker gene CXC ligand 1 were downregulated by candesartan, thereby decreasing infarct size. ${ }^{60}$

In addition to neuroprotection, candesartan exhibits poststroke neuroregenerative properties, as indicated by an upregulated expression of repair-associated proteins, such as MAP-2 and GAP-43. ${ }^{65}$ Because a substantial role of AT1 receptors in atherogenesis was uncovered, vasculoprotective properties of angiotensin II receptor antagonists independent of blood pressure effects are suggested. ${ }^{66}$ Indeed, the AT1 blocker losartan was found to exhibit antiatherogenic effects in nonhuman primates, as indicated by the inhibition of fatty-streak formation. ${ }^{67}$ Assumed underlying mechanisms gained from animal model and in vitro studies include a reduction of oxidative stress, inhibition of the inflammatory component of atherosclerotic lesion formation, inhibition of vascular smooth muscle cell proliferation, and a reduced intimal thickening. ${ }^{68-71}$

\section{Lipid-lowering drugs}

Hyperlipidemia is a well-established risk factor for myocardial infarction, whereas the effect of high serum cholesterol levels on stroke incidence is less clear. ${ }^{72,73}$ This might explain why statins, in contrast to other lipidlowering drugs, clearly prevent stroke recurrence in patients with prior stroke or other vascular diseases, irrespective of blood lipid levels at treatment initiation. ${ }^{74,75}$ These findings strongly suggest a multimodal mode of action.

Statins, or hydroxymethylglutaryl coenzyme A (HMG$\mathrm{CoA}$ ) reductase inhibitors, are similar to HMG-CoA, a precursor of cholesterol. Statins competitively inhibit HMG-CoA reductase, the rate-limiting step in the synthesis of cholesterol. ${ }^{76}$ Reduced intrahepatic cholesterol leads to an upregulated low-density lipoprotein (LDL) receptor activity with an increased clearance of LDL from the circulation.

Statins non-lipid-lowering effects, which are relevant in stroke pathophysiology, can be divided into two main groups: effects on the arterial vessels (including antiatherothrombotic and anti-inflammatory actions, as well as improvement of endothelial function) and direct neuroprotective and neuroregenerative effects on the brain (Table 1).

Atherosclerotic plaque-stabilizing effects of statins have been shown in both animal and human studies. ${ }^{77,78}$ Statins were found to mediate plaque stabilization by 
various mechanisms, including inhibitory effects on matrix metalloproteinases, inhibition of macrophage proliferation in atherosclerotic plaque, and induction of smooth muscle cell apoptosis. ${ }^{78,79}$ The so-called pleiotropic effects of statins include additional anti-inflammatory and antioxidant properties. C-reactive protein (CRP), which is a marker for inflammation associated with atherosclerosis, is reduced by statin therapy. ${ }^{80} \mathrm{Un}$ derlying mechanisms of the anti-inflammatory effects of statins include reduced leukocyte adhesion by integrin inhibition and inhibition of MHC-II-mediated T-cell activation. ${ }^{81,82}$ In addition, statins promote systemic antioxidant effects through suppression of distinct oxidation pathways, such as the formation of myeloperoxidasederived and nitric oxide-derived oxidants. ${ }^{83}$

The neuroprotective properties of statins have been shown in animal stroke models, in which statin therapy leads to reduced infarct volumes. ${ }^{84}$ The mechanisms of neuroprotection are presumably indirect effects, related to increased cerebral blood flow and improved endothelial function rather than to direct neuronal effects. The upregulation of brain endothelial nitric oxide synthase (eNOS) by statins with subsequent NO synthesis appears to be of particular importance. ${ }^{85,86}$ Statins suppress the isoprenoid production by HMG-CoA reductase inhibition and thereby prevent the isoprenylation of the small GTPase- $\rho$, a negative regulator of eNOS expression. ${ }^{87} \mathrm{In}$ addition, statins act via post-translational modification on eNOS activity by activation of the phosphatidylinositol 3-kinase-protein kinase Akt (PI3K-Akt) pathway. ${ }^{88} \mathrm{St}$ atins reduced the association of NMDA receptors to lipid rafts of neuronal cells in vitro, thus suggesting neuroprotective effects of statins mediated by protection from NMDA-induced neuronal damage. ${ }^{89}$

In addition to their neuroprotective effects, statins appear to have neuroregenerative properties post stroke. ${ }^{90,91}$ Atorvastatin improved functional recovery in a rat stroke model independent from infarct size reduction by enhancing neurogenesis, synaptogenesis, and angiogenesis. $^{91}$

\section{CANDIDATE DRUGS FOR ACUTE AND CHRONIC STROKE TREATMENT}

\section{Albumin}

Human albumin is in widespread use for fluid resuscitation in shock patients, although convincing evidence for this indication is lacking. ${ }^{92}$ Recently, high-dose human albumin (doses between $0.63 \mathrm{~g} / \mathrm{kg}$ and $2.5 \mathrm{~g} / \mathrm{kg}$ ) was studied in animal models of focal cerebral ischemia. ${ }^{93-96}$ Albumin reduced infarct size and improved functional recovery after permanent and temporary cerebral ischemia. ${ }^{94,97}$ Preclinical studies included a dose-response relationship evaluation and a time window investigation (up to 4 hours)..$^{93,94}$ Despite a reasonable number of preclinical albumin studies, the significance of the results is in some aspects weak. The studies showing efficacy of albumin in stroke animals were conducted in only one laboratory, only one species (rat) was tested, and only animals without comorbidities (e.g., diabetes or hypertension due to age) were included in the studies. ${ }^{98}$

Based on the preclinical results, a phase I doseescalation study, the Albumin in Acute Stroke (ALIAS) Pilot Trial, was conducted with 82 stroke patients. The results showed that albumin is safe in stroke patients. The authors of that study interpreted the results as a sign for efficacy, based on comparison of higher doses with lower doses and in comparison with a historical control group. ${ }^{99,100}$ A randomized, multicenter, double-blind, placebocontrolled trial (ALIAS Phase III Trial, www.clinicaltrials. gov; NCT00235495) is currently being conducted.

Animal stroke studies have suggested various mechanisms by which albumin provides an improved outcome after stroke. After middle cerebral artery occlusion (MCAO), albumin significantly reduced brain swelling in rats. ${ }^{94,101}$ Intravascular mechanisms (e.g., reduced adherence of thrombotic material and an improved erythrocyte perfusion) may also contribute to a beneficial outcome. ${ }^{95,102}$ Albumin mobilizes systemic fatty acids and may contribute to neural cell integrity post stroke by replenishing fatty acid lost from neural membranes during ischemia. ${ }^{103,104}$ In addition, albumin was suggested to exert anti-inflammatory effects by binding the proinflammatory lysolipid lysophosphatidylcholine. ${ }^{105}$ To date, however, convincing findings on the neuroprotective mode of action of albumin are lacking. The ALIAS pilot trial suggested a favorable outcome when thrombolysis was combined with albumin. ${ }^{100}$ Synergistic effects of albumin with thrombolysis were also demonstrated in a study using a rat stroke model in which the combination therapy improved microvascular hemodynamics. $^{96}$

\section{G-CSF}

The granulocyte colony-stimulating factor (G-CSF) is approved for the prevention and treatment of chemotherapy-induced neutropenia. ${ }^{106}$ Within the last several years, a number of reports showed efficacy of G-CSF in animal models of focal cerebral ischemia. ${ }^{107-111}$ To obtain an overall impression of the efficacy of G-CSF in preclinical studies and to evaluate conditions under which maximum efficacy can be achieved, we performed a meta-analysis and meta-regression analysis of G-CSF in animal stroke models. ${ }^{112}$ We showed that G-CSF reduced both infarct volumes and sensorimotor deficits. ${ }^{112}$ Our meta-regression analysis revealed a clear doseresponse relationship of the efficacy of G-CSF. ${ }^{112}$ When administered within the first 6 hours after the induction of ischemia, G-CSF reduced infarct sizes by $0.8 \%$ per 1 
$\mu \mathrm{g} / \mathrm{kg}$ body weight and by $2.1 \%$ per $1 \mu \mathrm{g} / \mathrm{kg}$ body weight when applied later than 6 hours. ${ }^{112}$

Based on these promising preclinical studies, a number of clinical studies were initiated to test the efficacy of G-CSF in stroke patients. ${ }^{113} \mathrm{We}$ conducted a multicenter, randomized, double-blind, placebo-controlled, dose-escalating phase IIa trial (AXIS), which was recently completed. ${ }^{114}$ In this trial, which included 45 patients who had suffered an acute stroke, G-CSF was shown to be safe and well-tolerated. In addition, G-CSF showed signs of clinical efficacy in patients with larger baseline lesions evidenced with diffusion MRI. ${ }^{114} \mathrm{~A}$ phase IIb/IIIa trial will start in the second quarter of 2009.

It cast doubt on the perception that G-CSF's natural function of mobilizing bone marrow stem cells is the most important mechanism, particularly since both GCSF and its receptor were found to be expressed in the brain (Table 1). ${ }^{107}$ In vitro and in vivo experiments confirmed that G-CSF acts antiapoptotically on neurons by at least three different antiapoptotic pathways: the signal transducer and activation of transcription 3 pathway (STAT-3), the extracellular signal-regulated kinase pathway (ERK), and the phophatidylinositol 3-kinase-Akt pathway (PI3K-Akt). ${ }^{107,108,111}$

Beyond the acute phase of stroke, G-CSF facilitates regeneration by enhancing endogenous neurogenesis. ${ }^{107}$ Another mechanism underlying long-term functional recovery appears to be angiogenesis, which was increased by G-CSF post stroke even when administered as late as 7 days after the induction of ischemia. ${ }^{109} \mathrm{G}-\mathrm{CSF}$ is well known for its immunomodulative properties. ${ }^{115} \mathrm{Al}$ though the exact effect of the G-CSF-mediated systemic immunomodulation on stroke outcome remains unknown, G-CSF obviously affects the local brain immune response post stroke. G-CSF treatment reduced infiltration of neutrophils and microglia in the ischemic hemisphere, and G-CSF lowered interleukin- $1 \beta$ upregulation. ${ }^{108,110,115}$

\section{Erythropoietin}

Erythropoietin (EPO) is in broad clinical use for the treatment of cancer-related anemia. ${ }^{116} \mathrm{EPO}$ is the second hematopoietic growth factor besides G-CSF to be extensively tested in preclinical stroke studies. ${ }^{117,118} \mathrm{~A}$ small clinical trial showed that EPO is safe and might be beneficial in acute ischemic stroke. ${ }^{119}$ The results of a randomized, double-blind, placebo-controlled multicenter study of EPO treatment in acute stroke has been completed, and results are expected in the near future (http:// www.clinicaltrials.gov; NCT00604630).

Erythropoietin parallels G-CSF in many respects with regard to the mode of action in ischemic stroke. Like G-CSF, EPO and its receptor are expressed in the brain. ${ }^{120}$ Notably, the EPO receptor that mediates neuroprotection seems to be distinct from those expressed by erythroid precursors. ${ }^{121}$ EPO also exerts antiapoptotic properties in vitro and in vivo. The JAK2-PI3K pathway was shown to be a key regulator in EPO-mediated neuroprotection. ${ }^{122}$ In addition to its neuroprotective effects, EPO has neuroregenerative properties by stimulating neuronal differentiation and neurogenesis, as evidenced in vitro and in vivo. ${ }^{117}$ After experimental stroke in mice, EPO restored local cerebral blood flow as measured by laser scanning imaging. ${ }^{123}$ Concordantly, histological examination showed enlarged vascular perimeters and an increased vascular density around the ischemic lesion, indicating an enhancement of angiogenesis after EPO treatment. ${ }^{117}$ EPO also modifies the inflammatory response after cerebral injury, as shown by reduced leukocyte infiltration after neonatal cerebral ischemia and reduced production of TNF $\alpha$ and IL-6. ${ }^{18,124}$

\section{Citicoline}

Citicoline is a dietary supplement. In some countries, it is in clinical use for the treatment of acute ischemic stroke. A meta-analysis of four clinical trials found that citicoline administration in stroke patients within the first 24 hours after symptom onset increases the probability of functional recovery at 3 months. ${ }^{125}$ A randomized, double-blind, placebo-controlled, multicenter phase III trial is currently recruiting patients to support this evidence (http://www.clinicaltrials.gov; NCT00331890).

Citicoline is an essential intermediate in the synthesis of the key membrane phospholipid phosphatidylcholine. ${ }^{126}$ Its role in maintaining membrane integrity was suggested as being a relevant mechanism in post-stroke recovery. After experimental stroke in rats, phospholipases (phosphatidylcholine degrading enzymes) are activated and CTP:phosphocholine cytidylyltransferase (CCT), the rate-limiting enzyme in phosphatidylcholine synthesis, is inactivated, both of which lead to neuronal cell death due to reduced phosphatidylcholine concentrations. ${ }^{127}$ Citicoline restores phosphatidylcholine levels by attenuating phospholipase activity and by enhancing CCT activity. ${ }^{127}$ Similar mechanisms were suggested for the preserving effects of citicoline on sphingomyelin and cardiolipin. ${ }^{128}$ Excessive neuronal stimulation with acetylcholine release after cerebral ischemia leads to choline depletion, which in turn induces apoptosis. ${ }^{129}$ Citicoline provides choline for the synthesis of acetylcholine and may thereby prevent apoptotic cell death in cholinergic neurons. The relevance of this mechanism was challenged, however, because acetylcholine concentrations were not significantly increased by citicoline treatment. ${ }^{130}$ In addition, citicoline was shown to reduce oxidative stress. ${ }^{128,131}$ 


\section{CONCLUSION}

Currently, multifunctional actions of stroke therapies are limited to drugs used for secondary stroke prevention. These drugs exhibit considerable properties beyond their classical mechanisms. In particular, statins show a broad range of pleiotropic effects that may be as important in stroke pathophysiology and recurrent stroke prevention as their lipid-lowering effects. In contrast to several drugs for secondary prevention of ischemic stroke, treatment options for the acute phase of stroke are limited to thrombolysis. Ongoing phase III clinical trials raise hope that additional treatment options for this acute phase will be available in the near future. This includes, in particular, drugs with multimodal modes of action that act on the brain itself, as well as on other systems such as the vasculature or the immune system.

\section{REFERENCES}

1. Davi G, Patrono C. Platelet activation and atherothrombosis. N Engl J Med 2007;357:2482-2494.

2. Savage B, Cattaneo M, Ruggeri ZM. Mechanisms of platelet aggregation. Curr Opin Hematol 2001;8:270-276.

3. Ruggeri ZM. Platelets in atherothrombosis. Nat Med 2002;8: $1227-1234$.

4. European Stroke Organisation (ESO) Executive Committee; ESO Writing Committee. Guidelines for management of ischaemic stroke and transient ischaemic attack 2008. Cerebrovasc Dis 2008;25:457-507.

5. Craven LL. Prevention of coronary and cerebral thrombosis. Miss Valley Med J 1956;78:213-215.

6. The Dutch TIA Trial Study Group. A comparison of two doses of aspirin (30 mg vs. $283 \mathrm{mg}$ a day) in patients after a transient ischemic attack or minor ischemic stroke. N Engl J Med 1991; 325:1261-1266.

7. International Stroke Trial Collaborative Group. The International Stroke Trial (IST): a randomised trial of aspirin, subcutaneous heparin, both, or neither among 19435 patients with acute ischaemic stroke. Lancet 1997;349:1569-1581.

8. Patrono C, García Rodriguez LA, Landolfi R, Baigent C. Lowdose aspirin for the prevention of atherothrombosis. N Engl J Med 2005;353:2373-2383.

9. De Cristóbal J, Moro MA, Dávalos, et al. Neuroprotective effect of aspirin by inhibition of glutamate release after permanent focal cerebral ischaemia in rats. J Neurochem 2001;79:456-459.

10. Berger C, Xia F, Schäbitz WR, Schwab S, Grau A. High-dose aspirin is neuroprotective in a rat focal ischemia model. Brain Res 2004;998:237-242.

11. Grilli M, Pizzi M, Memo M, Spano P. Neuroprotection by aspirin and sodium salicylate through blockade of NF- $\kappa \mathrm{B}$ activation. Science 1996;274:1383-1385.

12. Berger C, Stauder A, Xia F, Sommer C, Schwab S. Neuroprotection and glutamate attenuation by acetylsalicylic acid in temporary but not in permanent cerebral ischemia. Exp Neurol 2008; 210:543-548.

13. Zheng Z, Schwab S, Grau A, Berger C. Neuroprotection by early and delayed treatment of acute stroke with high dose aspirin. Brain Res 2007;1186:275-280.

14. Whitehead SN, Bayona NA, Cheng G, Allen GV, Hachinski VC, Cechetto DF. Effects of triflusal and aspirin in a rat model of cerebral ischemia. Stroke 2007;38:381-387.

15. Khayyam N, Thavendiranathan P, Carmichael FJ, Kus B, Jay V, Burnham WM. Neuroprotective effects of acetylsalicylic acid in an animal model of focal brain ischemia. Neuroreport 1999;10: $371-374$.
16. Bezzi P, Carmignoto G, Pasti L, et al. Prostaglandins stimulate calcium-dependent glutamate release in astrocytes. Nature 1998; 391:281-285.

17. Crisanti P, Leon A, Lim DM, Omri B. Aspirin prevention of NMDA-induced neuronal death by direct protein kinase $\mathrm{C} \zeta$ inhibition. J Neurochem 2005;93:1587-1593.

18. Maharaj H, Maharaj DS, Daya S. Acetylsalicylic acid and acetaminophen protect against oxidative neurotoxicity. Metab Brain Dis 2006;21:189-199.

19. Riepe MW, Kasischke K, Raupach A. Acetylsalicylic acid increases tolerance against hypoxic and chemical hypoxia. Stroke 1997;28:2006-2011.

20. Sanossian N, Saver JL, Rajajee V, et al. Premorbid antiplatelet use and ischemic stroke outcomes. Neurology 2006;66:319-323.

21. Wilterdink JL, Bendixen B, Adams HP Jr, Woolson RF, Clarke WR, Hansen MD. Effect of prior aspirin use on stroke severity in the trial of Org 10172 in acute stroke treatment (TOAST). Stroke 2001;32:2836-2840.

22. Lindsberg PJ, Grau AJ. Inflammation and infections as risk factors for ischemic stroke. Stroke 2003;34:2518-2532.

23. Kammersgaard LP, Jørgensen HS, Reith J, et al. Early infection and prognosis after acute stroke: the Copenhagen Stroke Study. J Stroke Cerebrovasc Dis 2001;10:217-221.

24. Paoletti R, Gotto AM Jr, Hajjar DP. Inflammation in atherosclerosis and implications for therapy. Circulation 2004;109(23 Suppl 1):III20-III26.

25. Marquardt L, Ruf A, Mansmann U, et al. Inflammatory response after acute ischemic stroke. J Neurol Sci 2005;236:65-71.

26. Ridker PM, Cushman M, Stampfer MJ, Tracy RP, Hennekens $\mathrm{CH}$. Inflammation, aspirin, and the risk of cardiovascular disease in apparently healthy men. N Engl J Med 1997;336:973-979.

27. Diener HC, Cunha L, Forbes C, Sivenius J, Smets P, Lowenthal A. European Stroke Prevention Study: 2. Dipyridamole and acetylsalicylic acid in the secondary prevention of stroke. J Neurol Sci 1996;143:1-13.

28. Halkes PH, van Gijn J, Kappelle LJ, Koudstaal PJ, Algra A. Aspirin plus dipyridamole versus aspirin alone after cerebral ischaemia of arterial origin (ESPRIT): randomised controlled trial [Erratum in: Lancet 2007;369:274]. Lancet 2006;367:1665-1673.

29. Gould KL, Westcott RJ, Albro PC, Hamilton GW. Noninvasive assessment of coronary stenoses by myocardial imaging during pharmacologic coronary vasodilatation: II. Clinical methodology and feasibility. Am J Cardiol 1978;41:279-287.

30. Ito H, Kinoshita T, Tamura Y, Yokoyama I, Iida H. Effect of intravenous dipyridamole on cerebral blood flow in humans: a PET study. Stroke 1999;30:1616-1620.

31. Heistad DD, Marcus ML, Gourley JK, Busija DW. Effect of adenosine and dipyridamole on cerebral blood flow. Am J Physiol 1981;240:H775-H780.

32. Costantini V, Talpacci A, Bastiano ML, et al. Increased prostacyclin production from human veins by dipyridamole: an in vitro and ex vivo study. Biomed Biochim Acta 1990;49:263-271.

33. Neri Serneri GG, Masotti G, Poggesi L, Galanti G, Morettini A. Enhanced prostacyclin production by dipyridamole in man. Eur J Clin Pharmacol 1981;21:9-15.

34. Iuliano L, Pedersen JZ, Rotilio G, Ferro D, Violi F. A potent chain-breaking antioxidant activity of the cardiovascular drug dipyridamole. Free Radic Biol Med 1995;18:239-247.

35. Iuliano L, Colavita AR, Camastra C, et al. Protection of low density lipoprotein oxidation at chemical and cellular level by the antioxidant drug dipyridamole. Br J Pharmacol 1996;119:14381446.

36. Farinelli SE, Greene LA, Friedman WJ. Neuroprotective actions of dipyridamole on cultured CNS neurons. J Neurosci 1998;18: 5112-5123.

37. Blake AD. Dipyridamole is neuroprotective for cultured rat embryonic cortical neurons. Biochem Biophys Res Commun 2004; 314:501-504.

38. Aldandashi S, Noor R, Wang CX, Uddin G, Shuaib A. Combination treatment with dipyridamole, aspirin, and tPA in an embolic model of stroke in rats. Exp Neurol 2007;205:563-568.

39. Picano E, Abbracchio MP. European Stroke Prevention Study-2 results: serendipitous demonstration of neuroprotection induced 
by endogenous adenosine accumulation? Trends Pharmacol Sci 1998;19:14-16.

40. Weyrich AS, Denis MM, Kuhlmann-Eyre JR, et al. Dipyridamole selectively inhibits inflammatory gene expression in plateletmonocyte aggregates. Circulation 2005;111:633-642.

41. Torry RJ, O'Brien DM, Connell PM, Tomanek RJ. Dipyridamole-induced capillary growth in normal and hypertrophic hearts. Am J Physiol 1992;262:H980-H986.

42. CAPRIE Steering Committee. A randomised, blinded, trial of clopidogrel versus aspirin in patients at risk of ischaemic events (CAPRIE). Lancet 1996;348:1329-1339.

43. Sacco RL, Diener HC, Yusuf S, et al. Aspirin and extendedrelease dipyridamole versus clopidogrel for recurrent stroke. N Engl J Med 2008;359:1238-1251.

44. Foster CJ, Prosser DM, Agans JM, et al. Molecular identification and characterization of the platelet ADP receptor targeted by thienopyridine antithrombotic drugs. J Clin Invest 2001;107: 1591-1598.

45. Savi P, Combalbert J, Gaich C, et al. The antiaggregating activity of clopidogrel is due to a metabolic activation by the hepatic cytochrome P450-1A. Thromb Haemost 1994;72:313-317.

46. Herbert JM, Tissinier A, Defreyn G, Maffrand JP. Inhibitory effect of clopidogrel on platelet adhesion and intimal proliferation after arterial injury in rabbits. Arterioscler Thromb 1993;13: 1171-1179.

47. Cortelekoglu T, Bozkurt AK, Ustundag N, Koksal C, Sayin AG. The effects of clopidogrel and calcium dobesilate on intimal hyperplasia following vascular injury. Acta Chir Belg 2006;106: 206-210.

48. Yang LH, Fareed J. Vasomodulatory action of clopidogrel and ticlopidine. Thromb Res 1997;86:479-491.

49. Huber R, Riepe MW. Improved posthypoxic recovery in vitro on treatment with drugs used for secondary stroke prevention. Neuropharmacology 2005;48:558-565.

50. PATS Collaborating Group. Post-stroke antihypertensive treatment study: a preliminary result. Chin Med J (Engl) 1995;108: $710-717$.

51. Schrader J, Lüders S, Kulschewski A, et al. Morbidity and mortality after stroke, eprosartan compared with nitrendipine for secondary prevention: principal results of a prospective randomized controlled study (MOSES). Stroke 2005;36:1218-1226.

52. Kizer JR, Dahlof B, Kjeldsen SE, et al. Stroke reduction in hypertensive adults with cardiac hypertrophy randomized to losartan versus atenolol: the Losartan Intervention for Endpoint Reduction in Hypertension study. Hypertension 2005;45:46-52.

53. Toffelmire EB, Slater K, Corvol P, Menard J, Schambelan M. Response of plasma prorenin and active renin to chronic and acute alterations of renin secretion in normal humans: studies using a direct immunoradiometric assay. J Clin Invest 1989;83: 679-687.

54. Naftilan AJ, Zuo WM, Inglefinger J, Ryan TJ Jr, Pratt RE, Dzau VJ. Localization and differential regulation of angiotensinogen mRNA expression in the vessel wall. J Clin Invest 1991;87: $1300-1311$.

55. Griendling KK, Lassègue B, Alexander RW. Angiotensin receptors and their therapeutic implications. Annu Rev Pharmacol Toxicol 1996;36:281-306.

56. Goodfriend TL, Elliott ME, Catt KJ. Angiotensin receptors and their antagonists. N Engl J Med 1996;334:1649-1654.

57. Burnier M, Brunner HR. Angiotensin II receptor antagonists. Lancet 2000;355:637-645.

58. Dai WJ, Funk A, Herdegen T, Unger T, Culman J. Blockade of central angiotensin AT receptors improves neurological outcome and reduces expression of AP- 1 transcription factors after focal brain ischemia in rats. Stroke 1999;30:2391-2398.

59. Lu Q, Zhu YZ, Wong PT. Neuroprotective effects of candesartan against cerebral ischemia in spontaneously hypertensive rats. Neuroreport 2005;16:1963-1967.

60. Schmerbach K, Schefe JH, Krikov M, et al. Comparison between single and combined treatment with candesartan and pioglitazone following transient focal ischemia in rat brain. Brain Res 2008; 1208:225-233.
61. Hosomi N, Nishiyama A, Ban CR, et al. Angiotensin type 1 receptor blockage improves ischemic injury following transient focal cerebral ischemia. Neuroscience 2005;134:225-231.

62. Polidori C, Ciccocioppo R, Pompei P, Cirillo R, Massi M. Functional evidence for the ability of angiotensin AT1 receptor antagonists to cross the blood-brain barrier in rats. Eur J Pharmacol 1996;307:259-267.

63. Bui JD, Kimura B, Phillips MI. Losartan potassium, a nonpeptide antagonist of angiotensin II, chronically administered p.o. does not readily cross the blood-brain barrier. Eur J Pharmacol 1992; 219:147-151.

64. Krikov M, Thone-Reineke C, Müller S, Villringer A, Unger T. Candesartan but not ramipril pretreatment improves outcome af ter stroke and stimulates neurotrophin BNDF/TrkB system in rats. J Hypertens 2008;26:544-552.

65. Liu H, Kitazato KT, Uno M, et al. Protective mechanisms of the angiotensin II type 1 receptor blocker candesartan against cerebral ischemia: in-vivo and in-vitro studies. J Hypertens 2008;26: $1435-1445$.

66. Wassmann S, Czech T, van Eickels M, Fleming I, Bohm M, Nickenig G. Inhibition of diet-induced atherosclerosis and endothelial dysfunction in apolipoprotein E/angiotensin II type 1A receptor double-knockout mice. Circulation 2004;110:30623067.

67. Strawn WB, Chappell MC, Dean RH, Kivlighn S, Ferrario CM Inhibition of early atherogenesis by losartan in monkeys with diet-induced hypercholesterolemia. Circulation 2000;101:15861593.

68. Oubiña MP, de Las Heras N, Vázquez-Pérez S, et al. Valsartan improves fibrinolytic balance in atherosclerotic rabbits. J Hypertens 2002;20:303-310.

69. Wolf SC, Sauter G, Rodemann HP, Risler T, Brehm BR. Influence of growth factors on the proliferation of vascular smooth muscle cells isolated from subtotally nephrectomized rats after endothelin or angiotensin II antagonism. Nephrol Dial Transplant 2005;20:312-318.

70. Doran DE, Weiss D, Zhang Y, Griendling KK, Taylor WR Differential effects of AT1 receptor and $\mathrm{Ca}^{2+}$ channel blockade on atherosclerosis, inflammatory gene expression, and production of reactive oxygen species. Atherosclerosis 2007;195:39-47.

71. Tsuda M, Iwai M, Li JM, et al. Inhibitory effects of AT1 receptor blocker, olmesartan, and estrogen on atherosclerosis via antioxidative stress. Hypertension 2005;45:545-551.

72. Piechowski-Jozwiak B, Bogousslavsky J. Cholesterol as a risk factor for stroke: the fugitive? Stroke 2004;35:1523-1524.

73. Thrift AG. Cholesterol is associated with stroke, but is not a risk factor. Stroke 2004;35:1524-1525.

74. Amarenco P, Bogousslavsky J, Callahan A III, et al. High-dose atorvastatin after stroke or transient ischemic attack. N Engl J Med 2006;355:549-559.

75. Corvol JC, Bouzamondo A, Sirol M, Hulot JS, Sanchez P, Lechat P. Differential effects of lipid-lowering therapies on stroke prevention: a meta-analysis of randomized trials. Arch Intern Med 2003;163:669-676.

76. Istvan ES, Deisenhofer J. Structural mechanism for statin inhibition of HMG-CoA reductase. Science 2001;292:1160-1164.

77. Schartl M, Bocksch W, Koschyk DH, et al. Use of intravascular ultrasound to compare effects of different strategies of lipidlowering therapy on plaque volume and composition in patients with coronary artery disease. Circulation 2001;104:387-392.

78. Crisby M, Nordin-Fredriksson G, Shah PK, Yano J, Zhu J, Nilsson J. Pravastatin treatment increases collagen content and decreases lipid content, inflammation, metalloproteinases, and cell death in human carotid plaques: implications for plaque stabilization. Circulation 2001;103:926-933.

79. Knapp AC, Huang J, Starling G, Kiener PA. Inhibitors of HMGCoA reductase sensitize human smooth muscle cells to Fas-ligand and cytokine-induced cell death. Atherosclerosis 2000;152:217227.

80. Plenge JK, Hernandez TL, Weil KM, et al. Simvastatin lowers C-reactive protein within 14 days: an effect independent of lowdensity lipoprotein cholesterol reduction. Circulation 2002;106: $1447-1452$. 
81. Weitz-Schmidt G, Welzenbach K, Brinkmann V, et al. Statins selectively inhibit leukocyte function antigen-1 by binding to a novel regulatory integrin site. Nat Med 2001;7:687-692.

82. Kwak B, Mulhaupt F, Myit S, Mach F. Statins as a newly recognized type of immunomodulator. Nat Med 2000;6:1399-1402.

83. Shishehbor MH, Brennan ML, Aviles RJ, et al. Statins promote potent systemic antioxidant effects through specific inflammatory pathways. Circulation 2003;108:426-431.

84. Sironi L, Cimino M, Guerrini U, et al. Treatment with statins after induction of focal ischemia in rats reduces the extent of brain damage. Arterioscler Thromb Vasc Biol 2003;23:322-327.

85. Asahi M, Huang Z, Thomas S, et al. Protective effects of statins involving both eNOS and tPA in focal cerebral ischemia. J Cereb Blood Flow Metab 2005;25:722-729.

86. Amin-Hanjani S, Stagliano NE, Yamada M, Huang PL, Liao JK, Moskowitz MA. Mevastatin, an HMG-CoA reductase inhibitor, reduces stroke damage and upregulates endothelial nitric oxide synthase in mice. Stroke 2001;32:980-986.

87. Laufs U, Liao JK. Post-transcriptional regulation of endothelial nitric oxide synthase mRNA stability by Rho GTPase. J Biol Chem 1998;273:24266-24271.

88. Kureishi Y, Luo Z, Shiojima I, et al. The HMG-CoA reductase inhibitor simvastatin activates the protein kinase Akt and promotes angiogenesis in normocholesterolemic animals. Nat Med 2000;6:1004-1010.

89. Ponce J, de la Ossa NP, Hurtado O, et al. Simvastatin reduces the association of NMDA receptors to lipid rafts: a cholesterol-mediated effect in neuroprotection. Stroke 2008;39:1269-1275.

90. Zheng Z, Chen B. Effects of pravastatin on neuroprotection and neurogenesis after cerebral ischemia in rats. Neurosci Bull 2007; 23:189-197.

91. Chen J, Zhang ZG, Li Y, et al. Statins induce angiogenesis, neurogenesis, and synaptogenesis after stroke. Ann Neurol 2003; 53:743-751

92. Finfer S, Bellomo R, Boyce N, French J, Myburgh J, Norton R. A comparison of albumin and saline for fluid resuscitation in the intensive care unit. N Engl J Med 2004;350:2247-2256.

93. Belayev L, Khoutorova L, Belayev A, et al. Delayed post-ischemic albumin treatment neither improves nor worsens the outcome of transient focal cerebral ischemia in rats. Brain Res 2004; 998:243-246.

94. Belayev L, Liu Y, Zhao W, Busto R, Ginsberg MD. Human albumin therapy of acute ischemic stroke: marked neuroprotective efficacy at moderate doses and with a broad therapeutic window. Stroke 2001;32:553-560.

95. Belayev L, Pinard E, Nallet H, et al. Albumin therapy of transient focal cerebral ischemia: in vivo analysis of dynamic microvascular responses. Stroke 2002;33:1077-1084.

96. Park HP, Nimmagadda A, DeFazio RA, Busto R, Prado R, Ginsberg MD. Albumin therapy augments the effect of thrombolysis on local vascular dynamics in a rat model of arteriolar thrombosis: a two-photon laser-scanning microscopy study. Stroke 2008; 39:1556-1562.

97. Liu Y, Belayev L, Zhao W, Busto R, Belayev A, Ginsberg MD. Neuroprotective effect of treatment with human albumin in permanent focal cerebral ischemia: histopathology and cortical perfusion studies. Eur J Pharmacol 2001;428:193-201.

98. Ginsberg MD. Life after cerovive: a personal perspective on ischemic neuroprotection in the post-NXY-059 era. Stroke 2007; 38:1967-1972.

99. Ginsberg MD, Hill MD, Palesch YY, Ryckborst KJ, Tamariz D. The ALIAS Pilot Trial: a dose-escalation and safety study of albumin therapy for acute ischemic stroke: I. Physiological responses and safety results. Stroke 2006;37:2100-2106.

100. Palesch YY, Hill MD, Ryckborst KJ, Tamariz D, Ginsberg MD. The ALIAS Pilot Trial: a dose-escalation and safety study of albumin therapy for acute ischemic stroke: II. neurologic outcome and efficacy analysis. Stroke 2006;37:2107-2114.

101. Matsui T, Sinyama H, Asano T. Beneficial effect of prolonged administration of albumin on ischemic cerebral edema and infarction after occlusion of middle cerebral artery in rats. Neurosurgery 1993;33:293-300.
102. Nimmagadda A, Park HP, Prado R, Ginsberg MD. Albumin therapy improves local vascular dynamics in a rat model of primary microvascular thrombosis: a two-photon laser-scanning microscopy study. Stroke 2008;39:198-204.

103. Rodriguez de Turco EB, Belayev L, Liu Y, et al. Systemic fatty acid responses to transient focal cerebral ischemia: influence of neuroprotectant therapy with human albumin. J Neurochem 2002; 83:515-524.

104. Belayev L, Marcheselli VL, Khoutorova L, et al. Docosahexaenoic acid complexed to albumin elicits high-grade ischemic neuroprotection. Stroke 2005;36:118-123.

105. Parkkinen J, Ojala P, Niiranen J, Jolkkonen J. Molecular mechanisms underlying neuroprotective effects of albumin after ischemic stroke. Stroke 2007;38:255.

106. Frampton JE, Lee CR, Faulds D. Filgrastim: a review of its pharmacological properties and therapeutic efficacy in neutropenia. Drugs 1994;48:731-760.

107. Schneider A, Krüger C, Steigleder T, et al. The hematopoietic factor G-CSF is a neuronal ligand that counteracts programmed cell death and drives neurogenesis. J Clin Invest 2005;115: 2083-2098.

108. Komine-Kobayashi M, Zhang N, Liu M, et al. Neuroprotective effect of recombinant human granulocyte colony-stimulating factor in transient focal ischemia of mice. J Cereb Blood Flow Metab 2006;26:402-413.

109. Lee ST, Chu K, Jung KH, et al. Granulocyte colony-stimulating factor enhances angiogenesis after focal cerebral ischemia. Brain Res 2005;1058:120-128.

110. Gibson CL, Jones NC, Prior MJ, Bath PM, Murphy SP. G-CSF suppresses edema formation and reduces interleukin- $1 \beta$ expression after cerebral ischemia in mice. J Neuropathol Exp Neurol 2005;64:763-769.

111. Schäbitz WR, Kollmar R, Schwaninger M, et al. Neuroprotective effect of granulocyte colony-stimulating factor after focal cerebral ischemia. Stroke 2003;34:745-751.

112. Minnerup J, Heidrich J, Wellmann J, Rogalewski A, Schneider A, Schäbitz WR. Meta-analysis of the efficacy of granulocyte-colony stimulating factor in animal models of focal cerebral ischemia. Stroke 2008;39:1855-1861.

113. Bath PM, Sprigg N. Colony stimulating factors (including erythropoietin, granulocyte colony stimulating factor and analogues) for stroke. Cochrane Database Syst Rev 2007;(2):CD005207.

114. Schäbitz WR, Laage R, Schwab S, et al. AX 200 (G-CSF) for the treatment of acute ischemic stroke (AXIS). 17th European Stroke Conference, Nice, France, May 13-16, 2008. Abstracts. Basel: Karger, 2008:62.

115. Hartung T, Von Aulock S, Schneider C, Faist E. How to leverage an endogenous immune defense mechanism: the example of granulocyte colony-stimulating factor. Crit Care Med 2003;31(1 Suppl):S65-S75.

116. Glaspy J, Beguin Y. Anaemia management strategies: optimising treatment using epoetin $\beta$ (NeoRecormon). Oncology 2005;69 Suppl 2:8-16.

117. Wang L, Zhang Z, Wang Y, Zhang R, Chopp M. Treatment of stroke with erythropoietin enhances neurogenesis and angiogenesis and improves neurological function in rats. Stroke 2004;35: 1732-1737.

118. Villa P, Bigini P, Mennini T, et al. Erythropoietin selectively attenuates cytokine production and inflammation in cerebral ischemia by targeting neuronal apoptosis. J Exp Med 2003;198:971975 .

119. Ehrenreich H, Hasselblatt M, Dembowski C, et al. Erythropoietin therapy for acute stroke is both safe and beneficial. Mol Med 2002;8:495-505.

120. Sirén AL, Knerlich F, Poser W, Gleiter CH, Brück W, Ehrenreich $\mathrm{H}$. Erythropoietin and erythropoietin receptor in human ischemic/ hypoxic brain. Acta Neuropathol 2001;101:271-276.

121. Brines M, Grasso G, Fiordaliso F, et al. Erythropoietin mediates tissue protection through an erythropoietin and common $\beta$-subunit heteroreceptor. Proc Natl Acad Sci U S A 2004;101:1490714912 . 
122. Ruscher K, Freyer D, Karsch M, et al. Erythropoietin is a paracrine mediator of ischemic tolerance in the brain: evidence from an in vitro model. J Neurosci 2002;22:10291-10301.

123. Li Y, Lu Z, Keogh CL, Yu SP, Wei L. Erythropoietin-induced neurovascular protection, angiogenesis, and cerebral blood flow restoration after focal ischemia in mice. J Cereb Blood Flow Metab 2007;27:1043-1054.

124. Sun Y, Calvert JW, Zhang JH. Neonatal hypoxia/ischemia is associated with decreased inflammatory mediators after erythropoietin administration. Stroke 2005;36:1672-1678.

125. Dávalos A, Castillo J, Alvarez-Sabín J, et al. Oral citicoline in acute ischemic stroke: an individual patient data pooling analysis of clinical trials. Stroke 2002;33:2850-2857.

126. Agut J, Font E, Sacristán A, Ortiz JA. Radioactivity incorporation into different cerebral phospholipids after oral administration of 14C methyl CDP-choline. Arzneimittelforschung 1983;33:10481050.

127. Adibhatla RM, Hatcher JF, Larsen EC, Chen X, Sun D, Tsao
FH. CDP-choline significantly restores phosphatidylcholine levels by differentially affecting phospholipase A2 and CTP: phosphocholine cytidylyltransferase after stroke. J Biol Chem 2006;281:6718-6725.

128. Adibhatla RM, Hatcher JF, Dempsey RJ. Effects of citicoline on phospholipid and glutathione levels in transient cerebral ischemia. Stroke 2001;32:2376-2381

129. Yen CL, Mar MH, Zeisel SH. Choline deficiency-induced apoptosis in PC12 cells is associated with diminished membrane phosphatidylcholine and sphingomyelin, accumulation of ceramide and diacylglycerol, and activation of a caspase. FASEB J 1999;13:135-142.

130. Kakihana M, Fukuda N, Suno M, Nagaoka A. Effects of CDPcholine on neurologic deficits and cerebral glucose metabolism in a rat model of cerebral ischemia. Stroke 1988;19:217-222.

131. Fresta M, Puglisi G, Di Giacomo C, Russo A. Liposomes as in-vivo carriers for citicoline: effects on rat cerebral post-ischaemic reperfusion. J Pharm Pharmacol 1994;46:974-981. 